\title{
Descripción del postcráneo de Rhipidomys austrinus y Graomys griseoflavus (Rodentia, Cricetidae, Sigmodontinae)
}

\author{
Luz V. Carrizo ${ }^{1,2}$ \& Mónica Díaz ${ }^{1,2,3}$ \\ 1. Programa de Investigaciones de Biodiversidad Argentina, Facultad de Ciencias Naturales e Instituto Miguel Lillo, Universidad Nacional de Tucumán, Miguel Lillo 205, Código Postal 4000, \\ San Miguel de Tucumán, Tucumán, Argentina. (luzvaleria.carrizo@gmail.com; mmonicadiaz@arnetbiz.com.ar) \\ 2. Consejo Nacional de Investigaciones Científicas y Técnicas. \\ 3. Programa de Conservación de los Murciélagos de Argentina.
}

\begin{abstract}
Postcranial description of Rhipidomys austrinus and Graomys griseoflavus (Rodentia, Cricetidae, Sigmodontinae). We described the postcranial skeleton of two species of sigmodontine rodents, Rhipidomys austrinus Thomas, 1921 and Graomys griseoflavus (Waterhouse, 1837). Each structure of the postcranial skeleton is here described in details of shape, size, surface, and orientation. The skeletal anatomy of these two species shows morphological characters associated with different patterns related to their type of locomotion. Rhipidomys austrinus exhibits characteristics consistent with its arboreal locomotion in several elements of the postcranium, while G. griseoflavus shows attributes related to terrestrial locomotion.
\end{abstract}

KEYWORDS. Sigmodontine rodents, Thomasomyini, Phyllotini, comparative anatomy.

RESUMEN. Se describe el esqueleto postcraneal de dos especies de roedores sigmodontinos Rhipidomys austrinus Thomas, 1921 y Graomys griseoflavus (Waterhouse, 1837). Se detalla cada estructura del esqueleto postcraneal sobre la base de la forma, tamaño, superficie y orientación de cada elemento esqueletal. La anatomía postcraneal de estas dos especies muestra caracteres asociados a patrones morfológicos diferentes, vinculados a su modo de locomoción. Es así que $R$. austrinus exhibe características en varios elementos del postcráneo consistente con una locomoción arborícola, mientras G. griseoflavus muestra atributos en su esqueleto relacionados a una locomoción de tipo terrestre.

PALABRAS-CLAVE. Roedores sigmodontinos, Thomasomyini, Phyllotini, anatomía comparada.

El postcráneo ha sido y es objeto de estudio en varios grupos de mamíferos, como primates, carnívoros, marsupiales, roedores (no sigmodontinos) y quirópteros, aportando relevantes contribuciones tanto a nivel taxonómico, filogenético como morfofuncional (HATT, 1932; Robert, 1974; TAYLOR, 1974, 1976; EVANS, 1993; Argot, 2001, 2002, 2003; SARGIS, 2001, 2002a, b; Horovitz \& SÁNchez-Villagra, 2003; Giannini \& Simmons, 2005; Morgan \& Verzi, 2006; CANDEla \& Picasso, 2008; Flores, 2009; Flores \& Díaz, 2009; Morgan, 2009). Sin embargo, el conocimiento sobre la anatomía postcraneal en los roedores sigmodontinos es nulo o escaso, especialmente si se compara con aquellos basados en la morfología externa, craneal y/o dentaria, aspectos intensamente estudiados en este grupo (Hershkovitz, 1962; Braun, 1993; Steppan, 1995; WEKSLER, 2006). Es por ello, que los estudios taxonómicos y filogenéticos en los sigmodontinos se han basado en los caracteres antes mencionados y recientemente se han incluido caracteres moleculares; sin tener en cuenta prácticamente ningún carácter de postcráneo. Solo algunos autores (STEPPAN, 1995; PACHECO, 2003; WEKSLER, 2006; PARDIÑAS et al., 2009; MACHADO et al., 2011) han incorporado en sus estudios información postcraneal, aunque solo para algunos elementos esqueletales y con descripciones poco detalladas.

Por lo dicho anteriormente es que estamos en posición de afirmar que este trabajo representará la base para futuros estudios en este tema y en este grupo en particular; ya que analiza de manera detallada y completa todos los elementos óseos de cada región del postcráneo de dos especies de sigmodontinos con hábitos muy diferentes. Rhipidomys austrinus Thomas, 1921, el único thomasomyino presente en Argentina, restringida a las Yungas del noroeste de Argentina (DíAZ et al., 2006a; JAYAT et al., 2006), es una especie de tamaño grande (longitud total 305-355 mm; peso 90-110 g), con locomoción trepador-arbórea (RIVAS \& LiNARES, 2006; RivAs et al., 2010; obs. pers. de los autores). Es una especie pobremente estudiada y la escasa información sobre su historia natural, en Argentina, fueron aportados por Olrog (1979), Massoia (1989) y DíAz (2002). Graomys griseoflavus (Waterhouse, 1837), la otra especie analizada corresponde a un filotino de tamaño grande (285-302 $\mathrm{mm}$; peso 60-110 g), de amplia distribución en Argentina (DíAz et al., 2006b), con locomoción terrestre (Hershkovitz, 1962). Sus poblaciones presentan un elevado rango de variación morfológica y de polimorfismo cromosómico (THEILER \& Gardenal, 1994; Theiler \& Blanco, 1996a, b; THeiler et al., 1999a, b; CATANESI et al., 2002).

La selección de los taxones se realizó, en el primero de ellos, por la falta de conocimiento en general de esta especie arborícola que cuenta con muy pocos registros en su área de distribución. Y en el caso de G. griseoflavus por tener una locomoción muy distinta a $R$. austrinus y por la gran cantidad de material que se cuenta a lo largo de su distribución en Argentina; además, surge la necesidad de encontrar caracteres en el postcráneo que ayuden a establecer una diagnosis más completa de esta especie ampliamente distribuida y con tantas variaciones individuales. 
En resumen, el objetivo principal de este estudio es incrementar el conocimiento de la anatomía postcraneal de los roedores sigmodontinos, proporcionando una descripción completa del postcráneo lo que permitirá definir caracteres que podrán ser utilizados desde un punto de vista filogenético o taxonómico, y además realizar un análisis comparativo en estas dos especies con diferente modo de locomoción donde se espera que el postcráneo presente distintos patrones morfológicos, ya que la variación de la morfología del sistema esqueletal está altamente vinculada con las variaciones en el modo de locomoción y uso de hábitat.

\section{MATERIAL Y MÉTODOS}

Se examinaron ocho ejemplares de $R$. austrinus y 13 de G. griseoflavus adultos de ambos sexos con material postcraneal completo y disponible en la Colección Mamíferos Lillo (CML) de la Universidad Nacional de Tucumán.

Se describe la morfología de cada parte del postcráneo (columna vertebral, cinturas y miembros), teniendo en cuenta la forma, superficie, tamaño y orientación de cada elemento esqueletal y la variación en número de todos los elementos óseos. Para una descripción más comprensible del postcráneo, este fue dividido en las siguientes regiones: morfología vertebral, cintura escapular y miembros anteriores, y cintura pélvica y miembros posteriores. Las estructuras esqueletales que presentan la misma morfología para ambas especies se describen de manera general. De lo contrario, si la estructura presenta diferencias entre las especies se describe la morfología para cada una de ellas.

Para la nomenclatura anatómica y criterios de posición de los huesos se siguieron, para los huesos del esqueleto axial a Hatt (1932), Evans (1993), Argot (2003) y Bezuidenhout \& Evans (2005); para huesos, forámenes y procesos de las cinturas y miembros anteriores y posteriores a Evans (1993), ARGOT (2001, 2002), Sargis (2002a,b), CANDela \& Picasso (2008), y FLORES \& DÍAZ (2009). Las estructuras homólogas fueron establecidas en base a la literatura (EvAns, 1993; ARGOT, 2001, 2002, 2003; Bezuidenhout \& Evans, 2005) y a través de la comparación morfológica de los ejemplares estudiados.

A fin de identificar los caracteres de importancia funcional que permitan inferir patrones morfológicos vinculados con el tipo de locomoción, la morfología esqueletal de estas dos especies fue comparada con el patrón evidenciado en otros mamíferos de locomoción arborícola y terrestre (marsupiales, carnívoros vivérridos, roedores), disponibles en trabajos publicados (TAYlor, 1974, 1976; ARGOT, 2001, 2002, 2003; SARgis, 2001, 2002a,b; Candela \& Picasso, 2008; Flores \& DíAz, 2009).
Especimenes examinados: Graomys griseoflavus: ARGENTINA Salta: Rivadavia, $31 \mathrm{~km}$ SSW Dragones along Río Bermejo $\left(23^{\circ} 29,62^{\prime} \mathrm{S}, 63^{\circ} 25,72^{\prime} \mathrm{W}\right), 308,16 \mathrm{~m}$, ㅇ, 14.VII.1993, J. K. Braun col. (CML 3570); ふ̃, 15.VII.1993, M. A. Mares col. (CML 3571); Formosa: Bermejo, $35 \mathrm{~km} \mathrm{S,} 5$ km E Ingeniero Guillermo Juárez, Puesto Divisadero ( $\left.24^{\circ} 11,66^{\prime} \mathrm{S}, 61^{\circ} 53,29^{\prime} \mathrm{W}\right)$, ô, 20.VII.1993, R. L. Humphrey col. (CML 3934); San Juan: Quebrada de las Flores, 4

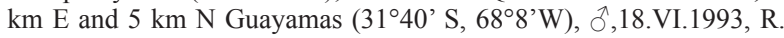
A. Ojeda col. (CML 3568); Mendoza: San Rafael, 2 km S Puesto Punta del Agua (35³4,23'S, 6803,59'W), 2700 ft., ふ̊, 08.V.1993, R. L Humphrey col. (CML 3558); ô, 05.VI.1993, R. A. Ojeda col. (CML 3557); San Luis: Capital, $6 \mathrm{~km}$ al oeste de Hualtarán, Parque Provincial Sierra de Las Quijadas (32²9,78'S, 670 $0,15^{\prime}$ W), 896 m, ㅇ, 20.V.1993, L. R. Humphrey col. (CML 3563); +, 22.V.1993, J. K. Braun col (CML 3564); 8 km W La Botija, Pampa de Las Salinas $\left(36^{\circ} 12,45^{\prime}\right.$ S, $\left.66^{\circ} 39,58^{\prime} \mathrm{W}\right), 1400$ ft., 17.V.1993, R. A. Ojeda col. (CML 3562); 12 km N Varela (by road), alt. 2200 ft., ふ̃, 03.VI.1990, M. Campbell col. (CML 3503); $15 \mathrm{~km}$ SE Salinas del Bebedero $\left(33^{\circ} 37,45^{\prime} \mathrm{S}\right.$, 66³5,79’W), 1000 ft, ふ̊, 02.VI.1993, L. R. Humphrey col. (CML 3566); $15 \mathrm{~km}$ E Salinas del Bebedero, $1350 \mathrm{ft}$, , , 21.IV.1990, M. A. Mares (CML 3508); Chubut: $8 \mathrm{~km}$ by road, E SE Puerto Madryn, 19,2 m, ふૈ, 14.XI.1991, M. A. Mares col. (CML 3927).

Rhipidomys austrinus: ARGENTINA, Salta: Dpto. San Martín,

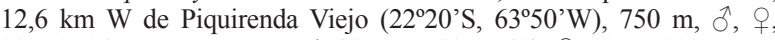
28.V.2004, R. M Barquez col. (CML 7748, 7749); ㅇ, 12.V.1999, R. M. Barquez col. (CML 7746); Dpto Orán, 43,7 km al NW del cruce de las rutas 50 y 18 , camino a Isla de Caña $\left(23^{\circ} 0,160^{\prime} \mathrm{S}, 64^{\circ} 33,161^{\prime} \mathrm{W}\right), 652$ m, + , 17.II.2006, L. I. Ferro (CML 7752); +, 06.V.2002, R. M. Barquez (CML 7747); Dpto Metán, Río de las conchas, 5,7 km al W de Metán, sobre el río, 996 m, ô, 12.I.2004, M. S. Sánchez (CML 7745); Jujuy: Dpto. Manuel Belgrano, $7 \mathrm{~km}$ al $\mathrm{N}$ de Las Capillas, sobre ruta provincial

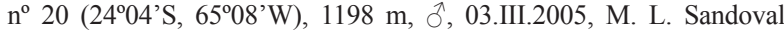
(CML 7750); Dpto. Santa Bárbara, ruta 6, 21,7 km al E de Santa Clara camino a El Fuerte $\left(24^{\circ} 18^{\prime}\right.$ S, 64 $34^{\circ}$ 'W), 1352 m, ô, 07. V. 2005, L. I. Ferro (CML 7751).

\section{RESULTADOS}

Morfología Vertebral. La columna vertebral en estas especies posee 7 vértebras cervicales, 12 (en G. griseoflavus) o 13 (en $R$. austrinus) torácicas, 6 lumbares, 3-4 sacras y 34-35 (en G. griseoflavus) o 3840 (en R. austrinus) caudales.

Atlas. En R. austrinus (Fig. 1) es deprimido y subtriangular, y en G. griseoflavus (Fig. 2) comprimido y redondeado. El arco neural, con los bordes craneal y caudal rectos, es más largo en $R$. austrinus. Los procesos transversos están reducidos, extendiéndose en G. griseoflavus más lateralmente. Los forámenes transversos son redondos. El tubérculo dorsal en $R$. austrinus le da un aspecto más triangular, en $G$. griseoflavus puede estar reducido o ausente. El foramen alar es redondo y puede ubicarse sobre el arco neural o el proceso espinoso. El tubérculo ventral está más desarrollado en $G$. griseoflavus, mientras que en $R$. austrinus es pequeño y orientado postero-ventralmente. Las facetas articulares craneales y caudales (Figs 1,2) están orientadas anteromedialmente, en G. griseoflavus las craneales son cóncavas y curvadas en la parte dorsal y las caudales ovaladas o redondas; mientras que en $R$. austrinus las primeras son cóncavas y las segundas ovaladas.

Axis. Es alto de forma subtriangular, en vista craneal; el arco neural es largo y el proceso espinoso es un tubérculo bajo, ancho en su base y el extremo distal 
levemente comprimido y truncado. En vista lateral el borde craneal y dorsal del proceso espinoso son convexos en $R$. austrinus y rectos en G. griseoflavus (Figs 3, 4). Los procesos transversos son cortos y orientados posteriormente, con el foramen transverso oval y de mayor tamaño en R. austrinus que en G. griseoflavus. El dens o proceso odontoides se orienta anterodorsalmente (Figs 3, 4). Las facetas craneales son redondeadas, ligeramente más expandidas dorsoventralmente en $R$. austrinus, de superficie plana y orientación cráneolateral. Las facetas caudales son ovaladas, de superficie plana y oblicuas.

Ventralmente, la vértebra es plana, ancha y se extiende posteriormente terminando en un proceso que articula con la siguiente vértebra; por lo general, en $G$. griseoflavus dicho proceso es más estrecho comparado con R. austrinus (Figs 3, 4).

Vértebras cervicales posteriores (C3-C7). Son bajas, siendo esta condición más evidente en G. griseoflavus. Los arcos neurales son cortos, con los bordes anterior y posterior rectos. En todas las cervicales de $G$. griseoflavus los procesos espinosos tienen forma de lámina, mientras que en $R$. austrinus la $\mathrm{C} 3-4$ son laminares y C5-C7 están reducidos a un tubérculo (Figs $3,4)$. Los procesos transversos en G. griseoflavus están orientados caudalmente, excepto en la C6 y C7 donde son subperpendiculares al eje de la columna; en $R$. austrinus en $\mathrm{C} 3$ y $\mathrm{C} 4$ se orientan caudalmente, en $\mathrm{C} 5$ son sub-perpendiculares y en $\mathrm{C} 6$ y $\mathrm{C} 7$ son perpendiculares. El foramen transverso sólo está ausente en la C7. En la C6 la lámina ventral, orientada caudalmente, tiene forma de yunque con el extremo distal extendido anteroposteriormente, en G. griseoflavus la extensión posterior de la lámina es mayor que en $R$. austrinus (Fig. 4). En vista ventral, las cervicales presentan superficie plana y articulan por medio de un proceso, más corto anteroposteriormente $\mathrm{y}$ ancho transversalmente en G. griseoflavus que en R. austrinus. (Figs 3, 4). Las articulaciones entre pre- y post-cigapófisis, respecto al plano sagital, son horizontales o levemente oblicuas en $R$. austrinus y oblicuas en G. griseoflavus.

Vértebras torácicas (T1-T12 o T13). Rhipidomys austrinus posee 13 vértebras torácicas y G. griseoflavus 12. Los arcos neurales son más largos en $R$. austrinus reduciendo el espacio intervertebral. Los procesos espinosos se orientan posteriormente, en $R$. austrinus son largos (excepto en T1) y a partir de la T7 se hacen bajos y alargados (Fig. 5), en G. griseoflavus son bajos (excepto en T2) y comienzan a aumentar su altura a partir de la T7 (Fig. 6). Las vértebras diafragmática y anticlinal muestran variación en su ubicación; en $R$. austrinus la diafragmática se ubica en T10 y la anticlinal en la T9 o T10, mientas que en G. griseoflavus en T9 o T10 y en T10 respectivamente (Figs 5, 6). Los procesos transversos están reducidos y llevan las facetas costales donde se insertan las costillas. Los procesos accesorios se desarrollan apartir de la T10 y se separan del proceso transverso en la T11 en R. austrinus y en T10 o T11 en $G$. griseoflavus. Los procesos mamilares son prominentes desde la T4 a T10 y se ubican más dorsalmente en $R$. austrinus. Los forámenes ventrales se encuentran, en general, uno por vértebra, pero en G. griseoflavus pueden registrarse dos por vértebra.

Vértebras lumbares (L1-L6 o L7). Rhipidomys austrinus posee seis vértebras lumbares y G. griseoflavus siete. Las vértebras lumbares comparadas con las torácicas son largas, comprimidas y de apariencia robusta. En vista dorsal, el espacio intervertebral es mayor en G. griseoflavus. Los procesos espinosos aumentan en altura caudalmente, en $R$. austrinus son más largos que en G. griseoflavus, pero en esta última especie estos se inclinan más anteriormente (Figs 9, 11). Los procesos transversos son delgados y orientados anteriormente, más levemente inclinados ventralmente en $R$. austrinus. Los procesos accesorios están desarrollados, siendo más alargados caudalmente en $R$. austrinus, y en la mayoría de los ejemplares examinados de G. griseoflavus dicho proceso está ausente en L5. Los procesos mamilares están presentes en todas las lumbares, en G. griseoflavus son más desarrollados y en $R$. austrinus, por lo general, se ubican anterior a la articulación de las cigapófísis. Los forámenes ventrales pueden estar ausentes o presentes (uno o dos). Las articulaciones entre pre- y postcigapófísis son oblicuas con respecto al plano sagital.

Vértebras sacras (S1-4). Ambas especies poseen cuatro sacras (Figs 9, 11) al igual que todos los sigmodontinos. La S1 está fusionada por completo al ilion y la S2 solo parcialmente. Los procesos transversos de las tres primeras sacras son largos anteroposteriormente, y en S4 son alargados, delgados y orientados anteriormente. El proceso espinoso de la S1, por lo general, es más alto y largo comparado con el resto de las sacras (Figs 9, 11). La cresta intermedia está bien desarrollada en $R$. austrinus y en menor grado o ausente en G. griseoflavus. Los dos primeros forámenes sacrales dorsales son ovalados en $R$. austrinus y redondos en $G$. griseoflavus. En vista ventral, el promontorio sacral y las líneas transversas están más marcadas en $R$. austrinus.

Vértebras caudales ( $\mathrm{Ca} \quad 34-35$ o $38-40)$. Rhipidomys austrinus presenta entre 38-40 y $G$. griseoflavus entre 34-35. Las primeras cuatro o cinco caudales muestran una morfología similar a las vértebras lumbares y sacras. Posteriormente, éstas se alargan, se estrechan y se reducen los elementos vertebrales (Figs $10,12)$. En $R$. austrinus las vértebras son más robustas y la articulación a través del cuerpo vertebral ocurre entre la cuarta y séptima caudal, y en G. griseoflavus entre la cuarta y sexta. Los procesos mamilares en $R$. austrinus comienzan a reducirse a partir de $\mathrm{Ca} 6$ y en G. griseoflavus de Ca3. Los procesos espinosos son bajos y largos, en $R$. austrinus están desarrollados en las cuatro primeras caudales y en G. griseoflavus en las tres primeras. En Ca1 los procesos transversos son largos y delgados, orientados lateralmente con respecto al cuerpo 


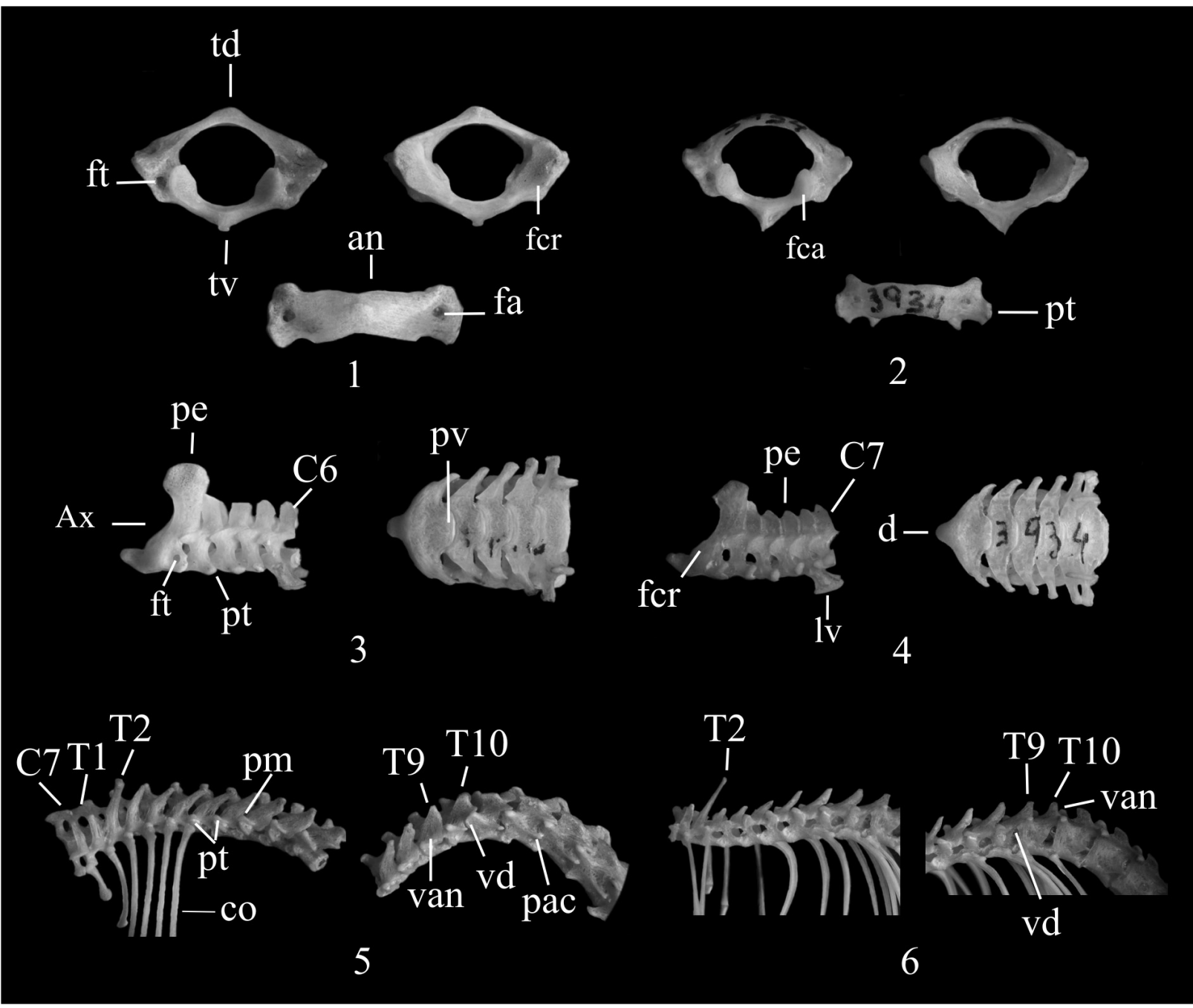

Figs. 1-6. Vista caudal, craneal y dorsal del atlas: 1, Rhipidomys austrinus (CML 7748); 2, Graomys griseoflavus (CML 3934). Vista lateral y ventral del axis y vértebras cervicales: $3, R$. austrinus; 4 , G. griseoflavus. Vista lateral de las vértebras torácicas: $5, R$. austrinus; $6, G$. griseoflavus (an, arco neural; Ax, axis; co, costillas; C6, sexta vértebra cervical; C7, séptima vértebra cervical; d, dens; fa, foramen alar; fca, faceta de articulación caudal; fcr, faceta de articulación craneal; ft, foramen transverso; lv, lámina ventral; pac, proceso accesorio; pe, proceso espinoso; pm, proceso mamilar; pt, proceso transverso; pv, proceso ventral; td, tubérculo dorsal; tv, tubérculo ventral; T1, T2, primera y segunda torácicas; T9, T10, novena y décima vértebras torácicas; van, vértebra anticlinal; vd, vértebra diafragmática).

vertebral, posteriormente a ésta los procesos se hacen ligeramente ventrales. Dichos procesos se reducen en tamaño a partir de Ca5 y desaparecen en la Ca12 en $G$. griseoflavus y la Ca15 en R. austrinus (Figs 10, 12). El arco hemal ocurre entre la 2 y 3 vértebra caudal y no forma un anillo en ninguna de las vértebras de estas dos especies.

Cintura escapular y miembros anteriores. Costilla y esternón: Rhipidomys austrinus posee 13 pares de costillas y $G$. griseoflavus 12 . Los 10 primeros pares de costillas se insertan en dos puntos, en la superficie de articulación de los procesos transversos y en los discos vertebrales; posteriormente, las dos (G. griseoflavus) o tres ( $R$. austrinus) últimas costillas articulan solo en los discos vertebrales. Como en todos los sigmodontinos, el primer par de costillas articula con la última cervical y la primera torácica; en $R$. austrinus son más anchas transversalmente, con el borde lateral convexo y el medial ligeramente más concavo, en contraste con $G$. griseoflavus donde son estrechas con bordes casi rectos. El resto de las costillas son cilíndricas y ligeramente más anchas craneocaudalmente en $R$. austrinus, mientras que en G. griseoflavus más comprimidas (Figs 5, 6).

El esternón está compuesto de seis esternebras, incluyendo manubrio y xifoide, separadas por cartílagos interesternebrales. El manubrio tiene forma de abanico con una marcada escotadura anterior, en G. griseoflavus es menos robusto y ligeramente quillado comparado con $R$. austrinus. En vista dorsal, las esternebras restantes son cortas y comprimidas, excepto la segunda que es más alargada. El proceso xifoide de $R$. austrinus es corto y aplanado; mientras que el de G. griseoflavus es alargado y comprimido.

Clavícula y escápula. La clavícula tiene el extremo escapular curvado y expandido, en $R$. austrinus es robusto y más curvado posteriormente que en $G$. griseoflavus. El extremo esternal es redondeado y su faceta de articulación es plana. 


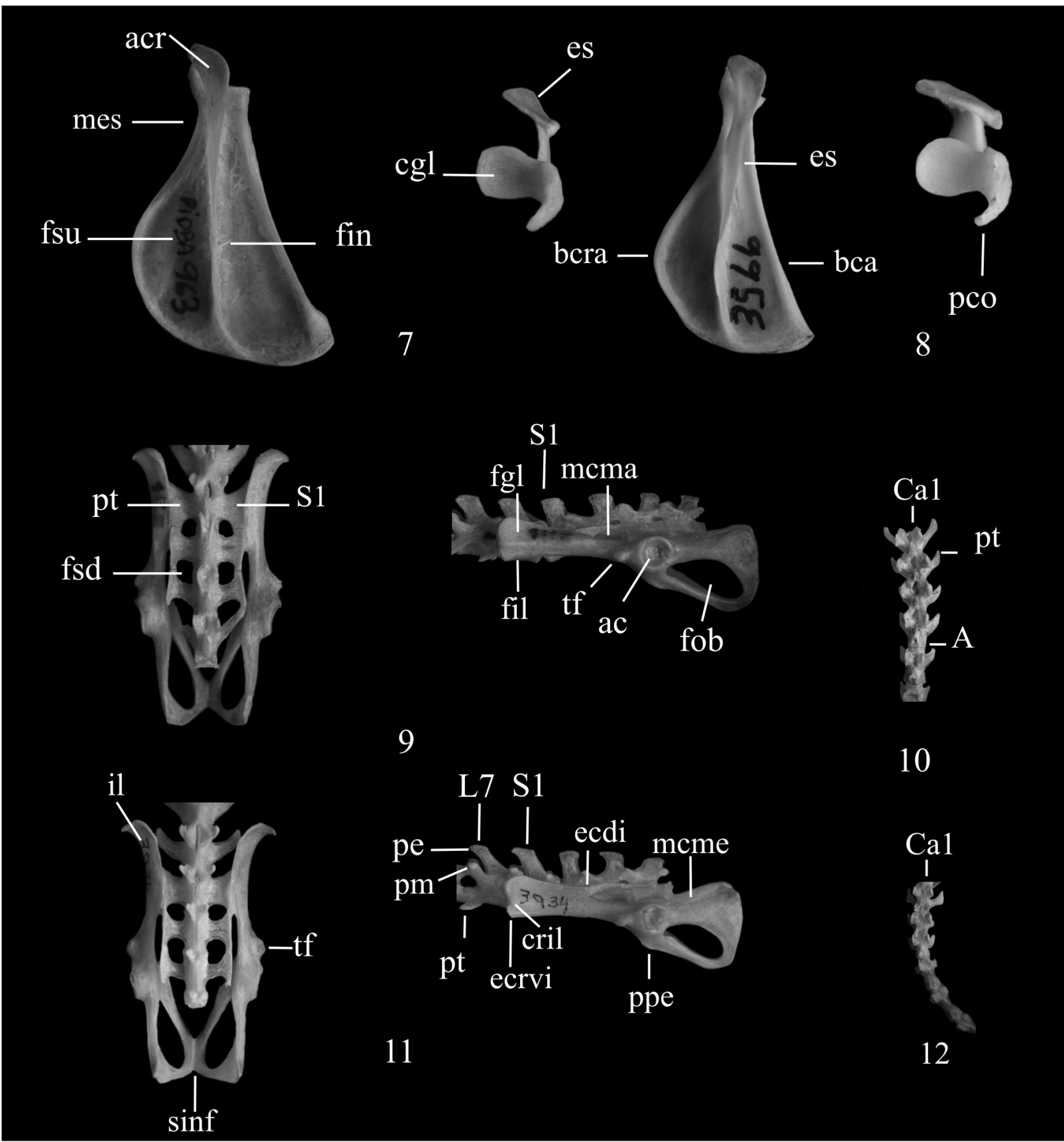

Figs. 7-12. Vista lateral y anterior de la escápula: 7, Rhipidomys austrinus (CML 7747); 8, Graomys griseoflavus (CML 3566). Vista dorsal y lateral de la pélvis, vértebras lumbares, sacras y vista dorsal de las caudales: 9, 10 R. austrinus (CML 7748); 11, 12 G. griseoflavus (CML 3934). (A, articulación a través del cuerpo; ac, acetábulo; acr, acromión; bca, borde caudal; bcra, borde craneal; Cal, primera vértebra caudal; cgl, cavidad glenoidea; cril, cresta ilíaca; ecdi, espina caudal dorsal ilíaca; ecrvi, espina craneal ventral ilíaca; es, espina; fgl, fosa gluteal; fil, fosa ilíaca; fin, fosa infraespinosa; fob, foramen obturador; fsd, forámenes sacrales dorsales; fsu, fosa supraespinosa; il, ilium; L7, séptima vértebra lumbar; mcma, muesca ciática mayor; mcme, muesca ciática menor; mes, muesca escapular; pco, proceso coracoides; pe, proceso espinoso; pm, proceso mamilar; ppe, proceso pectineal; pt, proceso transverso; sinf, sínfisis pélvica; S1, primera sacra; tf, tuberosidad femoralis).

En $R$. austrinus la escápula es ancha de forma subtriangular con las fosas supraespinosa e infraespinosa expandidas, mientras que en G. griseoflavus es estrecha con las fosas alargadas (Figs 7,8). La espina escapular es más alta en $R$. austrinus y desciende abruptamente con el borde externo convexo y en $G$. griseoflavus es baja con el borde recto. En vista lateral, en G. griseoflavus la espina está más inclinada hacia el borde caudal con el acromión ligeramente más alargado y el metacromion más marcado en comparación con $R$. austrinus (Figs 7, 8). La muesca escapular es más profunda en $G$. griseoflavus, en $R$. austrinus ésta se extiende hasta la mitad de la escápula (Fig. 7). El borde caudal es recto y el craneal es convexo, siendo la convexidad más marcada en $R$. austrinus. El ángulo caudal es agudo, en $R$. austrinus se extiende más posteriormente (Fig. 7). El proceso coracoides está curvado en dirección anteroventral, es largo en $R$. austrinus y corto en G. griseoflavus (Figs 7, 8). La 


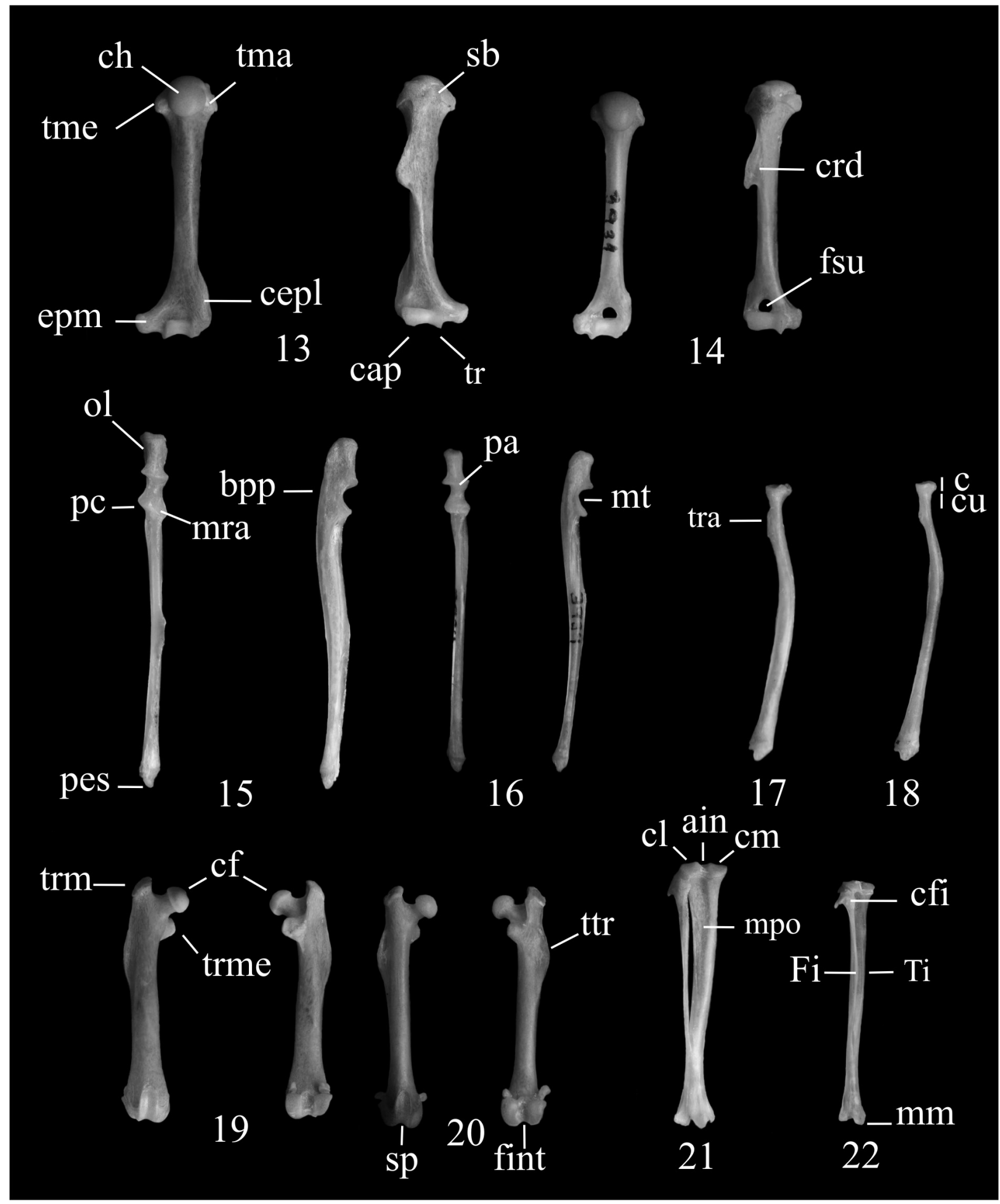

Figs. 13-22. Vista caudal y craneal del húmero: 13, Rhipidomys austrinus (CML 7748); 14, Graomys griseoflavus (CML 3934). Vista craneal y medial de la ulna: 15, R. austrinus; 16, G. griseoflavus. Vista lateral del radio: 17, R. austrinus; 18 , G. griseoflavus. Vista craneal y caudal del fémur: 19, R. austrinus; 20, G. griseoflavus. Vista caudal de tíbia y fibula: 21, R. austrinus; 22, G. griseoflavus (ain, área intercondilar; bpp, borde posterior proximal; c, cabeza; cap, capítulo; ch, cabeza humeral; cepl, cresta epicondilar lateral; cf, cabeza femoral; cfi, cabeza fibular; cl, cóndilo lateral; cm, cóndilo medial; crd, cresta deltopectoral; cu, cuello; epm, epicóndilo medial; Fi, fibula; fint, fosa intercondilar; fsu, foramen supratroclear; mm, maleolus medio; mpo, muesca poplítea; mra, muesca radial; mt, muesca troclear; ol, olécranon; pa, proceso anconeal; pc, proceso coracoide; pes, proceso estiloides; sb, surco bicipital; sp, surco patelar; Ti, tibia; tma, tubérculo mayor; tme, tubérculo menor; tr, tróclea; tra, tuberosidad radial; trm, trocánter mayor; trme, trocánter menor; ttr, tercer trocánter). 


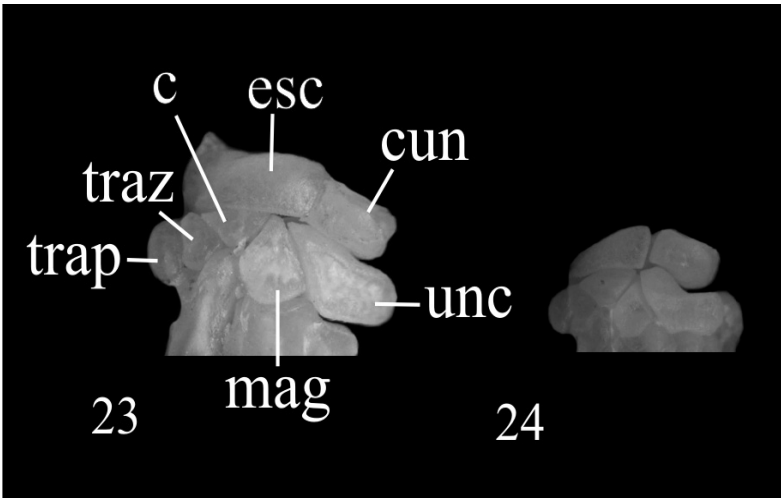

Figs. 23, 24. Vista dorsal de los huesos cárpales: 23, Rhipidomys austrinus (CML 7748); 24, Graomys griseoflavus (CML 3934) (c, central; cun, cuneiforme; esc, escafolunar; mag, magno; trap, trapecio; traz, trapezoide; unc, unciforme).

cavidad glenoidea en $G$. griseoflavus es redondeada y en $R$. austrinus es levemente ovalada y más profunda. El tubérculo supraglenoideo presenta mayor desarrollo en G. griseoflavus mientras que el tubérculo infraglenoideo no se observa en ninguna de las especies.

Húmero. El cuerpo es robusto con la diáfisis casi recta. La cabeza humeral es semiesférica en $R$. austrinus y se ubica por encima de los tubérculos mayor y menor; en G. griseoflavus es alargada anteroposteriormente y solo el tubérculo mayor se ubica levemente por encima de ésta (Figs 13, 14). El surco bicipital es más profundo en $R$. austrinus (Fig. 13). En vista lateral, la cresta deltopectoral es prominente extendiéndose hasta la mitad proximal de la diáfisis; en G. griseoflavus es muy saliente, terminado en punta, mientras que en $R$. austrinus es baja, con el extremo distal redondeado (Figs 13, 14). La tuberosidad del teres mayor se ubica más próximo al tubérculo deltoides en $R$. austrinus, siendo más evidente en $G$. griseoflavus. La tuberosidad del teres menor no se observa en ninguna de las especies.

En el extremo distal, la tróclea está claramente diferenciada del capítulo por un estrecho surco y presenta un borde medial prominente (Figs 13, 14). El capítulo está ligeramente más extendido proximalmente que la tróclea, es semiesférico en $R$. austrinus y plano en $G$. griseoflavus. En $R$. austrinus, el epicóndilo protruye medialmente separándose de la tróclea; siendo en $G$. griseoflavus la extensión medial mucho menor (Figs 13, 14). La cresta epicondilar lateral se extiende más proximalmente y con un mayor desarrollo en $R$. austrinus. El foramen entepicondilar está ausente, mientras que el foramen supratroclear está presente en G. griseoflavus y totalmente osificado R. austrinus (Fig. 13). Tanto la fosa del olécranon como la fosa radial son más profundas en G. griseoflavus.

Ulna y radio. La diáfisis de la ulna está comprimida, es ancha en su parte proximal y delgada distalmente (Figs 15,16 ), el borde posterior proximal en $R$. austrinus es convexo y en G. griseoflavus levemente convexo o recto. En la parte distal de la ulna el borde posterior se curva anteriormente, siendo más concavo en G. griseoflavus.
El olécranon es más corto en G. griseoflavus y largo y robusto en $R$. austrinus (Figs 15, 16). El proceso anconeal está pobremente desarrollado y la muesca troclear está relativamente abierta. El proceso coronoide protruye anteriormente y se inclina distalmente hacia la diáfisis, es comparativamente más ancho con respecto a la muesca radial y orientado medialmente en $R$. austrinus, mientras que en G. griseoflavus es estrecho y orientado más hacia la diáfísis (Figs 15, 16). La muesca radial, ligeramente cóncava, está orientada oblicuamente desde el proceso coronoide, en G. griseoflavus es ancha en comparación con $R$. austrinus. La fosa ulnar para el Musculus flexor digitorum profundus comienza a la altura de la muesca troclear y se extiende más de la mitad de la diáfisis; en G. griseoflavus es estrecha y profunda, y en $R$. austrinus es ancha y superficial. La fosa para inserción del M. anconeus, más profunda en $R$. austrinus, es evidente sobre el lado lateral. Sobre el lado craneal, la cresta para el $M$. pronator cuadratus está apenas marcada. Distalmente, se encuentra el proceso estiloide bien desarrollado que articula con el cuneiforme, más largo en $R$. austrinus que en G. griseoflavus (Figs 15, 16).

El cuerpo del radio es cilíndrico en $R$. austrinus y comprimido en G. griseoflavus (Figs 17, 18); en vista medial está anteroposteriormente curvado, dicha curvatura es más proximal en G. griseoflavus. En el extremo proximal, la cabeza es ovalada, en $R$. austrinus el borde posterior es levemente convexo y la fovea articular es más profunda. La circunferencia articular es estrecha y plana en G. griseoflavus, ancha y convexa en $R$. austrinus. El cuello es proporcionalmente más largo y comprimido en G. griseoflavus, con la tuberosidad radial poco desarrollada en comparación a $R$. austrinus. El extremo distal es cilíndrico con el proceso estiloides robusto y extendido más distalmente en $R$. austrinus (Fig. 17). La muesca ulnar, sobre la superficie lateral, es menos profunda y marcada en G. griseoflavus; y la superficie de articulación para el escafolunar es más cóncava y ancha (transversalmente) en $R$. austrinus. En la superficie dorsal son notables y profundos los surcos del tendón del M. abductor pollicis longus y de los extensores carpi radialis y digitalis comunis.

Carpo y mano. El carpo está formado por nueve huesos carpales (Figs 23, 24): escafolunar, pisiforme, cuneiforme, unciforme, magno, central, trapecio, trapezoide y sesamoide. El escafolunar es el hueso de mayor tamaño de la serie carpal, es transversalmente alargado y proximalmente se une con la epífisis del radio por medio de una faceta ancha transversalmente y de superficie plana. En $R$. austrinus el escafolunar es largo y en G. griseoflavus estrecho (Figs 23, 24). Lateralmente, articula con el cuneiforme por una superficie plana y en su extremo distal con el magno, trapecio, trapezoide y el central por una superficie cóncava a ligeramente plana. El cuneiforme, de forma rectangular, articula proximalmente con la epífisis de la ulna por una faceta 


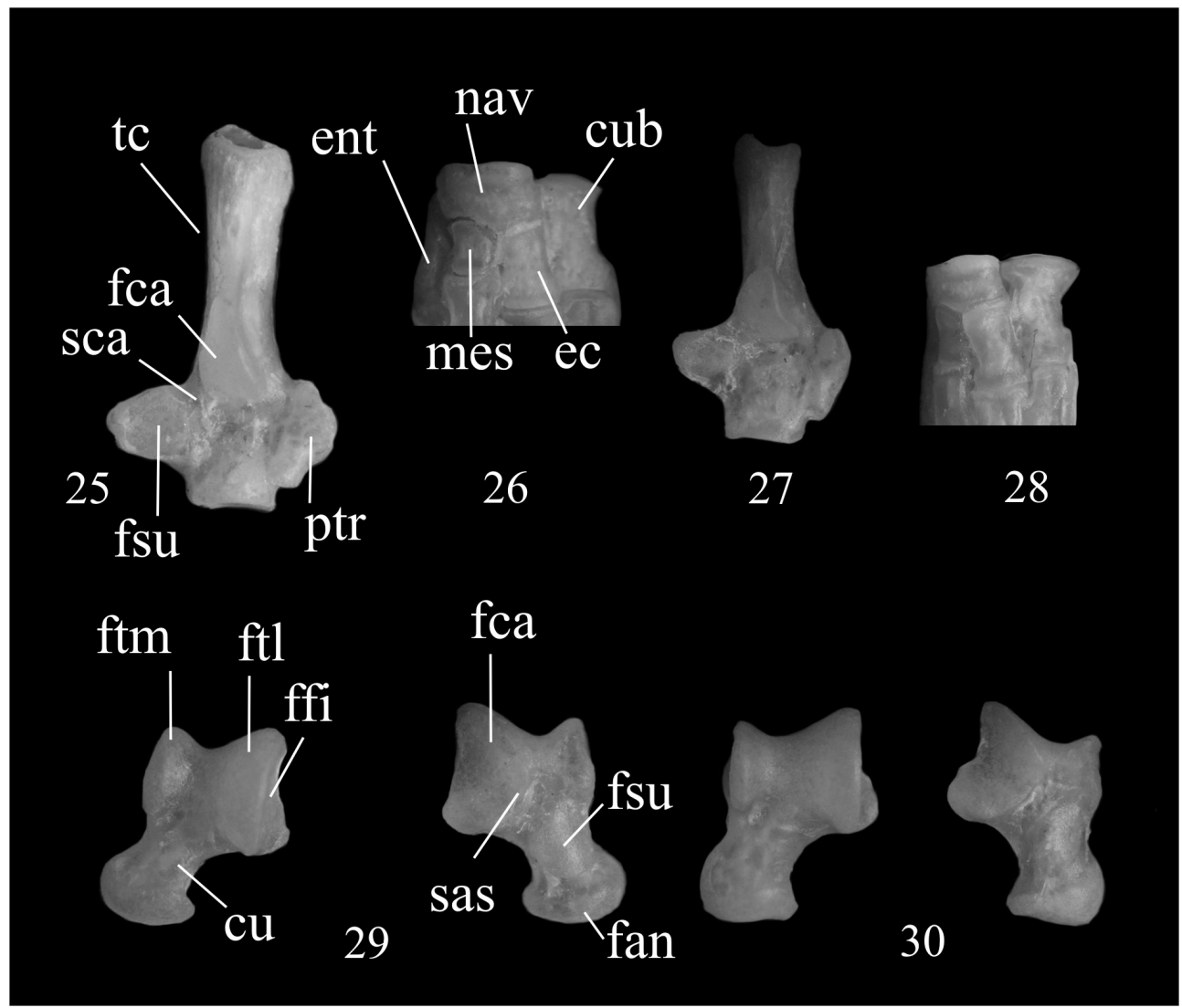

Figs. 25-30. Vista dorsal del calcáneo y los huesos tarsales: 25, 26, Rhipidomys austrinus (CML 7748); 27, 28, Graomys griseoflavus (CML 3934). Vista dorsal y ventral del astrágalo: 29, R. austrinus; 30, G. griseoflavus ( cub, cuboides; cu, cuello; ec, ectocuneiforme; ent, entocuneiforme; fan, faceta navicular; fca, faceta calcáneo astragalar; ffi, faceta fibular; fsu, faceta sustentacular; ftm, faceta tibial medial; ftl, faceta tibial lateral; mes, mesocuneiforme; nav, navicular; ptr, proceso troclear; sas, surco astragali; sca, surco calcáneo; tc, tubérculo calcáneo).

semicircular y cóncava, más profunda en R. austrinus, y distalmente con el unciforme por una superficie cóncavaconvexa, más profunda en $R$. austrinus. Sobre el lado palmar articula con el pisiforme a través de una superficie plana, este último hueso es más robusto y protruye más ventralmente en $G$. griseoflavus. El unciforme es más largo en $R$. austrinus (Fig. 23); contacta medialmente con el magno y el metacarpal III a través de una faceta plana; distalmente, se une con el metacarpal IV y V por medio de una superficie de articulación cóncava a ligeramente plana en $R$. austrinus y cóncava en G. griseoflavus. El magno de forma triangular, su superficie proximal convexa articula con el escafolunar, medialmente se une al central y al metacarpal II por una superficie plana y cóncava respectivamente y distalmente articula con el metacarpal III por una superficie cóncava. El central es pequeño y de forma triangular, se une con el trapezoide medialmente por una superficie plana y con el metacarpal II disto-medialmente por una faceta cóncava. El trapezoide de forma de rectángulo irregular, y el trapecio, ovalado, son similares en tamaño; en $R$. austrinus son proporcionalmente de mayor tamaño que en $G$. griseoflavus. Medialmente, el trapezoide se une con el trapecio y distalmente con el metatarsal II a través de una superficie convexa. El trapecio se extiende más ventralmente en $R$. austrinus, articula lateralmente con el metacarpal II y medialmente con el hueso sesamoide, por una superficie plana. El metacarpal I se une al trapecio, tanto medial como distalmente por una superficie plana. Sobre el lado palmar se encuentra el hueso sesamoide unido medialmente con el trapecio y curvado lateralmente, en G. griseoflavus es estrecho y en $R$. austrinus robusto.

Los metacarpales en $R$. austrinus son anchos, ligeramente cilíndricos y la cabeza para la unión con la falange proximal es robusta; mientras que en $G$. griseoflavus son delgados, levemente comprimidos lateralmente y la cabeza es menos robusta. El metacarpal I es corto en $R$. austrinus y largo en $G$. griseoflavus. La fosa para la inserción del tendón del $M$. extensor carpi ulnaris en el metacarpal $\mathrm{V}$ es profunda en $R$. austrinus y superficial en G. griseoflavus. El dígito I y V son más cortos que el resto de los dígitos, siendo esta condición más notable en $R$. austrinus. El dígito I o póllex es corto y robusto en $R$. austrinus y ligeramente largo y estrecho en G. griseoflavus. El dígito III y IV son largos en relación al resto, en $R$. austrinus son más cortos en comparación de G. griseoflavus. Las falanges proximales en $R$. austrinus son de longitud similar que los metacarpales, mientras que en G. griseoflavus son más cortas. Las falanges mediales son cortas comparadas con las proximales, en G. griseoflavus éstas son más cortas que 


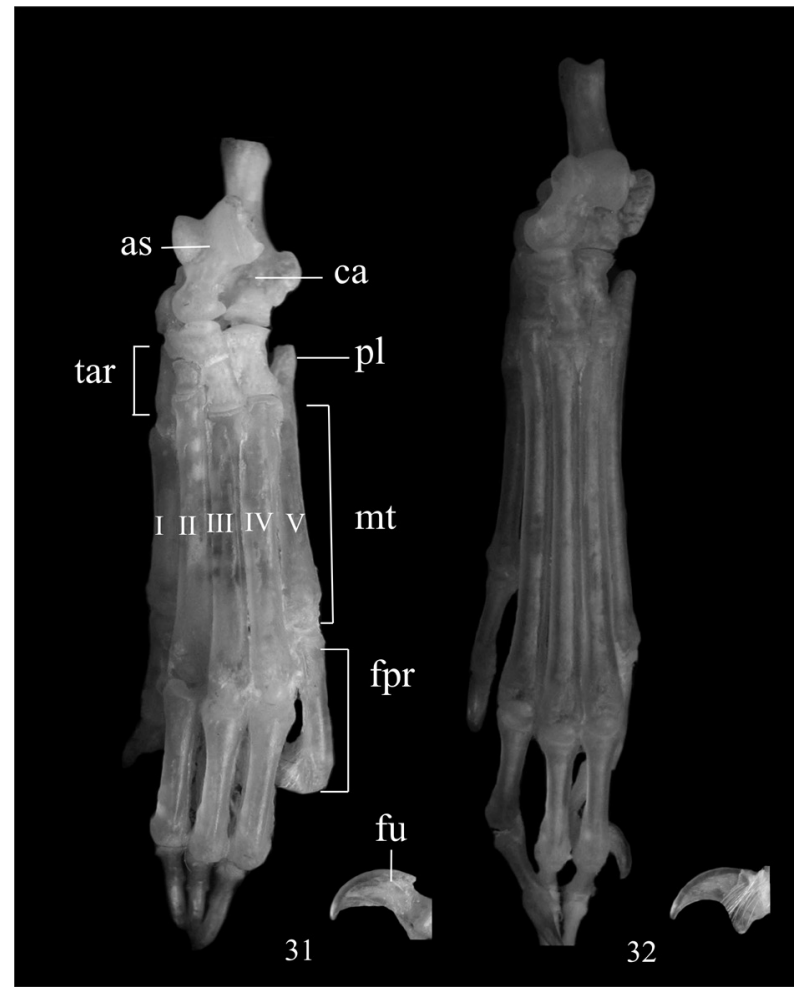

Figs. 31, 32. Vista dorsal del tarso y metatarso: 31, Rhipidomys austrinus (CML 7748); 32, Graomys griseoflavus (CML 3934) (as, astrágalo; ca, calcáneo; fpr, falanges proximales; fu, falanges unguales; mt, metatarsales; pl, proceso lateral; tar, tarso).

en $R$. austrinus. Las falanges ungual son cortas, anchas y curvadas en vista lateral en $R$. austrinus; mientras que en G. griseoflavus son largas, estrechas y apenas curvadas.

Cintura pélvica y miembros posteriores. Pelvis. El extremo anterior del ilion está lateralmente más curvado en G. griseoflavus que en R. austrinus (Figs 9, 11). La fosa gluteal, más desarrollada que la ilíaca, se inclina medialmente y es más cóncava en G. griseoflavus (Figs 9, 11). La cresta ilíaca está bien desarrollada. La espina dorsal caudal ilíaca está más desarrollada que la craneal y la espina craneal y caudal ilíaca ventral se encuentran bien marcadas. La muesca ciática mayor es cóncava y más evidente en $G$. griseoflavus que en $R$. austrinus donde es prácticamente recta.

En el isquion, la espina ciática es más convexa y evidente en $R$. austrinus y la muesca ciática menor es recta a diferencia de $G$. griseoflavus donde es levemente cóncava. En vista caudal, el arco ciático determina un ángulo agudo en $R$. austrinus y obtuso en $G$. griseoflavus. La tuberosidad ciática es una eminencia evidente en $G$. griseoflavus y apenas marcada en $R$. austrinus.

En el pubis, el proceso pectineal, ubicado ventral al acetábulo, es muy evidente, con un mayor desarrollo en $R$. austrinus (Figs 9, 11). El acetábulo es profundo y abierto, la superficie lunate es lisa y marcada, en $R$. austrinus es oval con el borde dorsal bien convexo, mientras que en $G$. griseoflavus es relativamente redondeado (Figs 9, 11). La tuberosidad para el $M$. rectus femoris está bien desarrollada. La sínfisis pélvica es corta en relación a la longitud del foramen obturador. El foramen obturador es ovalado, siendo en G. griseoflavus ligeramente más achatado dorsoventralmente y en $R$. austrinus es ancho con el borde dorsal más convexo.

Fémur. La cabeza femoral es esférica, apenas aplanada en la superficie articular, orientada apenas dorsomedialmente en $R$. austrinus y medialmente en $G$. griseoflavus. El cuello es proporcionalmente más corto en G. griseoflavus (Figs 19, 20). El trocánter mayor, que se extiende por encima de la cabeza, presenta una superficie dorsocaudal convexa en $R$. austrinus y plana en $G$. griseoflavus. El trocánter menor en $R$. austrinus es robusto y redondeado y en $G$. griseoflavus es triangular y se ubica apenas más caudalmente que en $R$. austrinus (Figs 19, 20). La fosa trocantérica es profunda y la cresta intertrocantérica está bien marcada, pudiendo ser el borde de la cresta recto o levemente convexo en la zona media. El tercer trocánter está bien desarrollado, en $G$. griseoflavus se ubica más proximalmente y en $R$. austrinus se extiende más distalmente sobre la diáfisis (Fig. 19). En la epifisis distal, el cóndilo medial y lateral similares en tamaño, son levemente convexos y separados por una fosa intercondilar ancha en $R$. austrinus y en G. griseoflavus son planos y la fosa es estrecha (Figs 19, 20). En vista craneal, el surco patelar es ancho en $R$. austrinus y estrecho en $G$. griseoflavus.

Patela. Tiene forma oval y curvada, en vista lateral, y articula con el surco patelar del fémur; la base, extremo proximal, es proporcionalmente más ancha en $R$. austrinus que en $G$. griseoflavus; mientras que el ápice, extremo distal, es más estrecho y termina en punta en ambas especies.

Tibia y fíbula. Estos huesos, que contactan en su área proximal y distal, están más separados entre sí en $R$. austrinus. La tibia, de forma sigmoidea en vista lateral, está comprimida en la parte lateral y caudal (Figs $21,22)$. En $R$. austrinus la articulación proximal es más ancha transversalmente y el cóndilo lateral es más cóncavo que el medial. La eminencia intercondílea tiene dos tubérculos, medial y lateral, bien marcados (Figs 21, 22). El área intercondilar es cóncava, más ancha en $R$. austrinus. La tuberosidad tibial se proyecta más cranealmente en G. griseoflavus y la cresta tibial es una superficie ligeramente convexa poco marcada. El área de origen del $M$. tibialis anterior, lateral a la cresta tibial, es cóncava en G. griseoflavus y superficial en $R$. austrinus. La muesca poplítea de $G$. griseoflavus es más profunda y estrecha (Figs 21, 22). En la epífisis distal, la faceta astrágalotibial lateral es cóncava, en $R$. austrinus es más larga que ancha y en $G$. griseoflavus es ligeramente más ancha que larga. El maleolus medial es una estructura prominente, siendo en $R$. austrinus más largo y robusto que en $G$. griseoflavus. La faceta astragalotibial medial, ubicada en el interior del maleolus medial, es corta (comparada con la astragalotibial lateral) y cóncava. En vista craneal, se observa la muesca semilunar y el surco para el $M$. flexor digitorum longus, dicho surco 
es ancho en $R$. austrinus y estrecho y extendido más proximalmente en $G$. griseoflavus. En vista caudal, se observa el surco para el M. flexor hallucis longus, apenas más cóncavo en G. griseoflavus que en R. austrinus.

La fíbula es notablemente más delgada que la tibia con el extremo proximal plano y el distal cilíndrico (Figs 21, 22). En vista caudal, el cuerpo fibular en $R$. austrinus es ancho transversalmente y ligeramente curvado, mientras que en G. griseoflavus es estrecho y prácticamente recto. La cabeza es robusta y articula lateralmente con la tibia en $R$. austrinus y en $G$. griseoflavus es estrecha y articula caudalmente (Fig. 22). Medialmente la cabeza es convexa en $R$. austrinus y plana en G. griseoflavus, lateralmente presenta una eminencia triangular, más desarrollada en $R$. austrinus. En la epífisis distal el maleolus lateral es más largo en $R$. austrinus con el surco para los músculos extensores poco evidente, mientras en G. griseoflavus dicho surco está bien marcado.

Calcáneo, astrágalo y pie. En el calcáneo, el tubérculo calcáneo es largo, con los procesos lateral y medial evidentes y separados por un surco ancho; dicho tubérculo es ancho en $R$. austrinus y relativamente comprimido lateralmente en G. griseoflavus (Figs 25, 27). El tubérculo plantar anterior es evidente, siendo más desarrollado en $R$. austrinus. La faceta calcáneoastragalar es triangular y convexa, en $R$. austrinus es más larga que en G. griseoflavus donde está orientada más medialmente con respecto al eje longitudinal (Fig. 25). La faceta sustentacular, de superficie plana, protruye más medialmente en $R$. austrinus. El surco calcáneo, entre las facetas sustentacular y calcáneo-astragalar, es más ancho y profundo en $R$. austrinus que en $G$. griseoflavus. El proceso troclear es ancho en $R$. austrinus y su extremo proximal se ubica por encima del borde distal de la faceta calcáneo-astragalar, mientras que en G. griseoflavus es estrecho y se ubica casi al mismo nivel del borde distal de la faceta (Fig. 27). Sobre el lado palmar del tubérculo peroneal se encuentra el surco para el tendón del M. peroneus longus es ancho y profundo en $R$. austrinus y estrecho y superficial en G. griseoflavus. La faceta calcáneo-cuboide es semicircular, ligeramente cóncava en $R$. austrinus y plana en G. griseoflavus. En el astrágalo (Figs 29, 30), el cuerpo es subcuadrangular y asimétrico; siendo la faceta astrágalo-tibial lateral (= cóndilo lateral) mas robusta, ancha y de pendiente más suave que la faceta astrágalo-tibial medial. En $R$. austrinus la faceta tibial medial y lateral son más prominentes y separados por un surco estrecho y profundo (Fig. 29); mientras que en G. griseoflavus la faceta tibial medial es más prominente que la lateral y el surco es ancho y superficial (Fig. 30). La faceta fibular, ubicada lateral a la faceta astragalo-tibial lateral, es de forma semicircular, ancha y suavemente cóncava. El cuello del astrágalo es proporcionalmente más largo en G. griseoflavus (Fig. 30 ). La cabeza astragalar en $R$. austrinus es convexa y se orienta apenas medialmente, mientras que en $G$. griseoflavus es plana y más lateralmente orientada (Figs 29, 30). Sobre el lado plantar, la tuberosidad medial es evidente, más prominente en $R$. austrinus. La faceta sustentacular en $R$. austrinus es redondeada y medialmente orientada y en G. griseoflavus es alargada y orientada ventralmente. El surco astragali es notable y profundo. La faceta astrágalo-navicular es ancha, convexa y orientada medialmente en $R$. austrinus y plana o convexa y ventralmente orientada en $G$. griseoflavus.

El cuboides, de forma irregular, es alargado con la zona medial estrecha; en G. griseoflavus dicha zona está más comprimida (Fig. 28). El proceso medial es evidente y protruye medialmente en G. griseoflavus, siendo en $R$. austrinus reducido. Medialmente articula con el navicular por medio de una faceta pequeña y plana, y con el ectocuneiforme a traves de dos facetas, una más proximal (mayor) y una distal (pequeña) ambas de superficie plana. En G. griseoflavus estas dos últimas facetas son más pequeñas comparado con $R$. austrinus. Anteriormente articula con el metatarsal IV, por una superficie ligeramente cóncava, y con el metatarsal V por una faceta ubicada lateroventralmente y de superficie plana. Sobre el lado plantar, es evidente el surco para el M. peroneus longus, el cual es oblicuo y profundo; sin embargo en $R$. austrinus dicho surco es más ancho que en $G$. griseoflavus. El navicular es rectangular y proporcionalmente más largo en $R$. austrinus, en $G$. griseoflavus se estrecha más en su parte medial (Figs 26, 28). La faceta navicular-mesocuneiforme es cóncava (condición más evidente en $R$. austrinus) mientras que la navicular-ectocuneiforme es plana. La faceta navicularentocuneiforme tiene forma triangular y es ligeramente convexa, en $R$. austrinus es ancha y orientada ventromedialmente, mientras que en G. griseoflavus es estrecha y orientada mesialmente. El ectocuneiforme es rectangular y medialmente articula con el metatarsal II en su mitad anterior y con el mesocuneiforme en la posterior, ambos por una faceta plana. Lateralmente aparte de contactar con el cuboides, su parte más distal articula con el metatarsal IV, mientras anteriormente articula con el metatarsal III a través de una faceta ancha y plana. El mesocuneiforme es cuadrado en $R$. austrinus y rectangular en G. griseoflavus (Figs 26, 28), articula medialmente con el entocuneiforme por intermedio de una faceta cóncava y distalmente contacta con el metatarsal II por medio de una faceta larga y plana. El entocuneiforme es alargado, en vista medial es alto en $R$. austrinus y bajo en G. griseoflavus, lateralmente articula con el mesocuneiforme y el metatarsal II por una faceta plana, y por el extremo anterior con el metatarsal I a través de una faceta cóncava.

Los metatarsales son largos, rectos y ligeramente aplanados en G. griseoflavus y cortos, cilíndricos y ligeramente cóncavos ventralmente con la cabeza más globular en $R$. austrinus (Figs 31, 32). Los metatarsales I y V son más cortos que los otros tres, en $R$. austrinus son robustos y más cortos que en G. griseoflavus (Fig. 31). 
La epífisis proximal del MtI es de forma troclear, en $R$. austrinus el surco es más profundo y en $G$. griseoflavus el borde lateral es más largo que el medial. El proceso lateral del MtV no se extiende más allá del extremo proximal del cuboide, en $R$. austrinus es más prominente y separado desde la faceta de articulación con el cuboide que en G. griseoflavus (Fig. 31). Las falanges proximales son cortas en relación a los metatarsales, en $R$. austrinus representan la mitad de su longitud y en $G$. griseoflavus un tercio. Las falanges mediales en $R$. austrinus representan casi la mitad de la longitud de las falanges proximales, mientras que en G. griseoflavus son similares en longitud. Las falanges unguales son largas, en $R$. austrinus son robustas y dorsoventralmente curvadas, mientras que en G. griseoflavus son estrechas y apenas curvadas (Figs 31, 32).

\section{DISCUSIÓN}

En los roedores sigmodontinos la forma $\mathrm{y}$ tamaño de las vértebras son constantes, no obstante las estructuras vertebrales (p.e. procesos espinosos, transversos, accesorios, entre otros) muestran una importante variación en forma, tamaño y orientación, caracterizando a cada región de la columna vertebral. Algunas de estas estructuras fueron descriptas en trabajos sistemáticos y filogenéticos (p.e. STEPpan, 1995; PACheco, 2003; WeKsler, 2006), y los caracteres considerados se comparan con nuestros resultados.

En la columna vertebral, $R$. austrinus presenta 13 vértebras torácicas y 7 lumbares, condición descrita para el género Rhipidomys Tschudi, 1844 y roedores sigmodontinos en general (CARLETON, 1980; Steppan, 1995; Pacheco, 2003); mientras que en $G$. griseoflavus es de 12 torácicas y 7 lumbares, no típica para sigmodontinos, pero coincide con lo observado por StepPAn (1995) para filotinos. STEPPAN (1995) observó en el axis de los filotinos un proceso espinoso de forma tubercular, condición observada tanto en G. griseoflavus como en $R$. austrinus. Según Voss (1988) en los sigmodontinos es común que el proceso espinoso sobre T2 sea más largo que el de las vértebras adyacentes, esta condición se observó en $G$. griseoflavus pero no en $R$. austrinus, donde el proceso espinoso es alto tanto en T2 como en T3. WeKSLER (2006) reporta la presencia de una anapófísis en la TL17 (= L5), como una condición taxonómicamente variable en los sigmodontinos; en las especies aquí estudiadas dicha estructura fue registrada solo en $R$. austrinus. El número de vértebras caudales encontrado en G. griseoflavus (34-35) y en R. austrinus (38-40) coinciden con lo observado por STEPPAN (1995) y PACheCo (2003) para ambas especies. Por otro lado, según Steppan (1995) el arco hemal en la mayoría de las especies de sigmodontinos no forma un arco completo; sin embargo, PACHECO (2003) reporta la presencia de un arco para una sola especie de Rhipidomys $(R$. leucodactylus (Tschudi, 1845)). En los ejemplares examinados de $R$. austrinus y G. griseoflavus el arco hemal no forma un arco completo en ninguna vértebra caudal.

Con respecto a las cinturas y a los miembros anteriores y posteriores, las estructuras se diferencian principalmente en su forma, tamaño, superficie y orientación; y ciertas características encontradas en este trabajo fueron definidas ya por otros autores para otros taxones. Así CARLETon (1980) describe en la escápula de los roedores Gerbillidae una tercera fosa a lo largo del borde axilar, además de la supra e infraespinosa. Esta condición se observa en la escápula de $R$. austrinus donde el ángulo caudal se extiende posteriormente y en el cual se fijaría el $M$. teres major. En el húmero, el foramen entepicondilar está ausente en ambas especies examinadas, condición considerada una potencial sinapomorfia para los sigmodontinos (VOSS \& CARLETON, 1993; Steppan, 1995; Pacheco, 2003; Weksler, 2006). La ausencia del foramen supratroclear en $R$. austrinus concuerda con lo observado por STEPPAN (1995), PACHeCo (2003) para el género.

En el calcáneo, CARLETON (1980) observó que el proceso troclear $(=$ proceso peroneal) puede ubicarse proximalmente por encima de la faceta calcáneoastragalar o estar separado de ésta por un espacio, e indicó la primera condición como plesiomorfica para neotomine-peromyscines. Para STEPPAN (1995) la presencia de un espacio entre el proceso troclear y la faceta es una sinapomorfia potencial de los sigmodontinos. Esta condición se presenta en todos los ejemplares examinados de G. griseoflavus y coincide con lo observado por STEPPAN (1995) para esta especie, mientras que en $R$. austrinus el proceso se ubica por encima de la faceta, condición observada por PACHECO (2003) para algunos thomasomyinos, pero no registrada para el género Rhipidomys. Según PACheco (2003), el dígito I y el dígito $\mathrm{V}$ del pie son, por lo general, más largos en thomasomyinos que en filotinos. Esto concuerda con $R$. austrinus donde las falanges proximales son largas, comparadas con las de G. griseoflavus, y los dígitos son más largos. El proceso peroneal (= proceso lateral) del $\mathrm{MtV}$ de los thomasomyinos y filotinos no se extiende más allá del extremo proximal del cuboide (STEPPAN, 1995; PACHECO, 2003); lo que fue observado en ambas especies estudiadas.

Desde un punto de vista comparativo, las características morfológicas observadas en el postcráneo de $R$. austrinus y G. griseoflavus permiten diferenciar dos esquemas estructurales o patrones morfológicos vinculados con su tipo de locomoción. Es así, que varios caracteres en el postcráneo de $R$. austrinus se pueden relacionar con adaptaciones de una locomoción arborícola; sin embargo, dichos caracteres no son tan marcados como aquellos observados en marsupiales, carnivoros vivérridos y primates con una gran capacidad arborícola (ROBERT, 1974; TAYLOR, 1974, 1976; ARGOT, 2001, 2002, 2003). 
En la columna vertebral se encuentran caracteres que le otorgan más rigidez y estabilidad (p.e. procesos accesorios desarrollados, menor inclinación anterior de los procesos espinosos), y que están asociados a músculos que permiten realizar los movimientos típicos de formas arborícolas (ARGOT, 2003; Flores \& DíAz, 2009). Asimismo, las cinturas y los miembros anteriores y posteriores presentan un conjunto de caracteres relacionados a este tipo de locomoción (p.e. escápula ancha, proceso coracoide de la escápula largo, cresta pectoral del húmero prominente, epicóndilo medial humeral bien desarrollado, proceso coracoide ulnar orientado medialmente) y dichos caracteres están involucrados en los movimientos de flexión, aducción y elevación de los miembros (TAYlor, 1974; Argot, 2001, 2002; Sargis, 2002a,b; Candela \& Picasso, 2008; Flores \& DíAz, 2009). La anatomía de los huesos carpales, tarsales y de las facetas articulares muestran atributos (p.e. faceta proximal ancha del escafolunar, faceta astrágalo-navicular ancha, proceso peroneal del calcáneo desarrollado) que permiten movimientos laterales y rotacionales, indicativos de una gran capacidad de flexibilidad asociada a una locomoción arbórea. En los metacarpales, metatarsales y falanges, la morfología general observada (p.e. falange proximal tan larga como los metacarpales, fosa profunda en el $\mathrm{McV}$, proceso lateral desarrollado del Mt V) sugiere una leve capacidad prensil (TAYLOR, 1974; ARGOT, 2001; FLORES \& DíAZ, 2009). Finalmente, la forma del proceso ungual (robusto, ancho y dorsoventralmente curvado) es consistente con el morfotipo encontrado en otras especies de locomoción arborícola e indica un rango de incremento en la dorsiflexión-plantarflexión (ARGOT, 2002; Flores \& Díaz, 2009) esencial para este tipo de locomoción.

En contraste, el postcráneo de G. griseoflavus presenta características asociadas a una locomoción terrestre. En la columna vertebral se identifican caracteres (p.e. procesos espinosos lumbares delgados y orientados anteriormente, anapofísis poco desarrollada) vinculados funcionalmente con el incremento en la flexibilidad del cuerpo y en los movimientos verticales y laterales, necesarios en este tipo de locomoción. Las cinturas y los miembros anteriores y posteriores exhiben condiciones (p.e. escápula estrecha, tubérculo mayor y menor por arriba de la cabeza humeral, epicóndilo medial reducido, extremo anterior del ilium curvado lateralmente) relacionadas a un mayor rango de extensión y de menor movilidad en sus articulaciones, limitando los movimientos a un plano parasagital (ARGOT, 2001; SARGIS, 2002a,b). LAS características de los huesos carpales y tarsales (p.e. faceta astrágalo-navicular orientada ventralmente, extensión palmar del pisiforme) son consistentes con formas de locomoción terrestre (TAYLOR, 1974; ARGOT, 2001, 2002; SARGIS, 2002 a,b), ya que influyen en la distribución de las cargas, estabilidad y en la movilidad de las articulaciones, y permiten movimientos de flexión y extensión más que de supinación y pronación. La anatomía general de los metacarpales, metatarsales y falanges (p.e. póllex y hállux alargado, metacarpales y metatarsales alargados y rectos) incrementa la rigidez plantar y la longitud del paso (TAYLOR, 1974; Argot, 2001, 2002). Por último, el proceso ungual es largo y estrecho, característico de las especies con una locomoción terrestre (ARGOT, 2001, 2002).

Agradecimientos. Agradecemos al curador de la Colección Mamíferos Lillo Dr. Rubén Barquez por permitir el acceso al material de estudio. A los miembros del PIDBA (Programa de Investigaciones de Biodiversidad Argentina) por su colaboración. Al CONICET por el apoyo a este trabajo.

\section{REFERENCIAS BIBLIOGRAFICAS}

Argot, C. 2001. Functional-adaptive anatomy of the forelimb in the Didelphidae, and the paleobiology of the Paleocene marsupials Mayulestes ferox and Pucadelphys andinus. Journal of Morphology 247:51-79.

2002. Functional-adaptive analysis of the hindlimb anatomy of extant marsupials and paleobiology of the Paleocene marsupials Mayulestes ferox and Pucadelphys andinus. Journal of Morphology 253:76-108.

2003. Functional-adaptative anatomy of the axial skeleton of some extant marsupials and the paleobiology of the Paleocene marsupials Mayulestes ferox and Pucadelphys andinus. Journal of Morphology 255:279-300.

Bezuidenhout, A. J. \& Evans, H. E. 2005. Anatomy of woodchuck (Marmota monax). American Society of Mammalogist, Special publication, (13):1-180.

Braun, J. K. 1993. Systematic relationships of the Tribe Phyllotini (Muridae: Sigmodontinae) of South American. Norman, Oklahoma Museum of Natural History. Special Publications. 50p.

Candela, A. \& Picasso, M. B. J. 2008. Functional anatomy of the limbs of Erethizontidae (Rodentia, Caviomorpha): indicators of locomotor behavior in Miocene Porcupines. Journal of Morphology 269:552-593.

Carleton, M. D. 1980. Phylogenetic relationships of neotomineperomyscine rodents (Muroidea) and a reappraisal of the dichotomy within New World Cricetinae. Miscellaneous Publications Museum of Zoology, University of Michigan 157:1-146.

Catanesi, C. I.; Vidal-Rioja, L.; Crisci, J. V. \& Zambelli, A. 2002. Phylogenetic relationships among Robertsonian karyomorphs of Graomys griseoflavus (Rodentia, Muridae) by mithocondrial cytochrome b DNA sequencing. Hereditas 136:130-136.

Díaz, M. M. \& Barquez, R. M. 2002. Los mamíferos de Jujuy Argentina. Buenos Aires, Literature of Latin America. 308p.

Díaz, M. M.; Pardiñas, U. F. J. \& Barquez, R. M. 2006a. Tribu Thomasomyini. In: Barquez, R. M.; Díaz, M. M. \& OjedA, R. A. eds. Mamíferos de Argentina: sistemática y distribución. Tucumán, Sociedad Argentina para el Estudio de los Mamíferos. p.191-192.

Díaz, M. M.; Teta P.; Pardiñas U. F. J. \& Barquez, R. M. 2006b. Tribu Phyllotini. In: Barquez, R. M.; Díaz, M. M. \& Ojeda, R. A. eds. Mamíferos de Argentina: sistemática y distribución. Tucumán, Sociedad Argentina para el Estudio de los Mamíferos. p.175-189.

Evans, H. E. 1993. Miller's Anatomy of the dog. 3. ed. Philadelphia, W.B. Saunders. $1113 p$.

Flores, D. A. 2009. Phylogenetic analyses of postcranial skeletal morphology in didelphid marsupials. Bulletin of the American Museum of Natural History 320:1-81.

Flores, D. A. \& DíAz, M. M. 2009. Postcranial skeleton of Glironia venusta (Didelphimorphia, Didelphidae, Caluromyinae): description and functional morphology. Zoosystematics and Evolution 85(2):311-339.

Giannini, P. N. \& Simmons, N. B. 2005. Conflict and congruence in a combined DNA- morphology analysis of megachiroptera bat relatioships (Mammalia: Chiroptera: Pteropodidae). Cladistics 21(5):411-437. 
Hatt, T. R. 1932. The vertebral columns of Ricochetal Rodents. Bulletin of The American Museum of Natural History 63:599738.

Hershkovitz, P. 1962. Evolution of Neotropical cricetine rodents (Muridae) with special reference to the phyllotini group. Fieldiana: Zoology 46:1-524.

Horovitz, I. \& SÁnchez-Villagra, M. R. 2003. A morphological analysis of marsupial mammal higher-level phylogenetic relationships. Cladistics 19:181-212.

Jayat, J. P.; Ortiz, P. E.; Teta, P.; Pardiñas, U. F. J \& D’Elia, G. 2006. Nuevas localidades Argentinas para algunos roedores sigmodontinos (Rodentia: Cricetidae). Mastozoología Neotropical 13(1):51-67.

Machado, L. F.; Paresque, R. \& Christoff, A. U. 2011. Anatomia comparada e morfometria de Oligoryzomys nigripes e $O$. flavescens (Rodentia, Sigmodontinae) no Rio Grande do Sul, Brasil. Papéis Avulsos de Zoologia 51(3):29-47.

Massoia, E. 1989. Nuevo o poco conocidos cráneos de mamíferos vivientes- 1- Rhipidomys leucodactylus austrinus de la provincia de Salta, República Argentina. Asociación para la Protección de la Naturaleza, Boletín Científico 15:14-16.

Morgan, C. C. 2009. Geometric morphometrics of the scapula of south American caviomorph rodents (Rodentia: Hystricognathi): from, function and phylogeny. Mammalian Biology 74:497-506.

Morgan, C. C. \& Verzi, D. H. 2006. Morphological diversity of the humerus of the south american subterranean rodent ctenomys (Rodentia, Ctenomyidae). Journal of Mammalogy 87(6):12521260 .

Olrog, C. C. 1979. Los Mamíferos de la selva húmeda, Cerro Calilegua, Jujuy. Acta Zoológica Lilloana 33:19-14.

PACHeCO, V. R. 2003. Phylogenetic analyses of the Thomasomyini (Muroidea: Sigmodontinae) based on morphological data. Ph.D. dissertation. The City University of New York. 398 p. (Unpublished).

Pardiñas, U. F. J.; Teta, P. \& D’Elia, G. 2009. Taxonomy and distribution of Abrawayaomys (Rodentia: Cricetidae), an Atlantic Forest endemic with the description of a new species. Zootaxa 2128:39-60.

Rivas，B. A.; D’Elia, G. \& Liñares, O. 2010. Diferenciación morfológica en sigmodontinos (Rodentia: Cricetidae) de las Guayanas venezolanas con relación a su locomoción y hábitat. Mastozoología Neotropical 17(1):97-109.

Rivas, B. A. \& Liñares, O. J. 2006. Cambios en la forma de la pata posterior entre roedores sigmodontinos según su locomoción y hábitat. Mastozoología Neotropical 13:205-215.

Robert, D. 1974. Structure and Function of the Primate Scapula. In: Jenkins JR, F. A. ed. Primate Locomotion. New York, Academic. p.171-200.
SARGIS, E. J. 2001. The grasping behaviour, locomotion and substrate use of the tree shrews Tupaia minor and T. tana (Mammalia Scandentia). Journal of Zoology London 253:485-490.

2002a. Functional morphology of the forelimb of tupaiids (Mammalia, Scandentia) and its phylogenetic implications. Journal of Morphology 253:10-42.

2002b. Functional morphology of the hindlimb of tupaiids (Mammalia, Scandentia) and its phylogenetic implications. Journal of Morphology 254:149-185.

Steppan, S. J. 1995. Revision of the Tribe Phyllotini (Rodentia: Sigmodontinae), with a phylogenetic hypothesis for the Sigmodontinae. Fieldiana: Zoology, New Series, 8:1-112.

TAYLOR, M. E. 1974. The functional anatomy of the forelimbs of some African Viverridae (Carnivora). Journal of Morphology 143:307-336.

.1976. The functional anatomy of the hindlimbs of some African Viverridae (Carnivora). Journal of Morphology 148:227-254.

Theiler, G. R. \& Blanco, A. 1996a. Patterns of evolution in Graomys griseoflavus (Rodentia, Muridae): III. Olfatory discrimintaion as a premating isolation mechanism between cytotypes. Journal of Experimental Zoology 274:346-350.

. 1996b. Patterns of evolution in Graomys griseoflavus (Rodentia, Muridae): II. Reproductive isolation between cytotypes. Journal of Mammalogy 77:776-784.

Theiler, G. R. \& Gardenal, C. N. 1994. Patterns of evolution in Graomys griseoflavus (Rodentia, Cricetidae). I. Protein polymorphism in populations with different chromosome number Hereditas 120:225-229.

Theiler, G. R.; Gardenal, C. N. \& Blanco, A. 1999a. Patterns of evolution in Graomys griseoflavus (Rodentia, Muridae). IV A case of rapid speciation. Journal of Evolutionary Biology 12:970-979.

Theiler, G. R.; Ponce, R. H.; Fretes, R. E. \& Blanco, A. 1999b. Reproductive barriers between the 2ns42 and 2ns36-38 cytotype of Graomys (Rodentia: Muridae). Mastozoologia Neotropical 6:129-133.

Voss, R. S. 1988. Systematics and ecology of ichthyomyine rodents (Muroidea): patterns of morphological evolution in a small adaptative radiation. Bulletin of the American Museum of Natural History 188:259-493.

Voss, R. S. \& CARLETON, M. D. 1993. A new genus for Hesperomys molitor Winge and Holochilus magnus Hershkovitz, with comments on phylogenetic relationships and oryzomyine monophyly. American Museum Novitates 3085:1-39.

WeKSLER, M. 2006. Phylogenetic relationships of oryzomyine rodents (Muroidea: Sigmodontinae): separate and combined analyses of morphological and molecular data. Bulletin of the American Museum of Natural History 296:1-149. 